\title{
Correction to: Advances in Manufacturing Engineering
}

\author{
Seyed Sattar Emamian, Mokhtar Awang, and Farazila Yusof
}

\section{Correction to:}

S. S. Emamian et al. (eds.), Advances in Manufacturing

Engineering, Lecture Notes in Mechanical Engineering, https://doi.org/10.1007/978-981-15-5753-8

The original version of the chapter "Performance Evaluation on the Smartness of Malaysian Timber" has been revised. "Acknowledgement" section included.

And

The original version of the chapter "A Review of Recent Developments in Mechanical Properties of Polymer-Clay Nanocomposites" has been revised. In the Introduction section last two paras has been removed.

The correction chapters and the book have been updated with changes.

The updated version of these chapters can be found at https://doi.org/10.1007/978-981-15-5753-8_11

https://doi.org/10.1007/978-981-15-5753-8_13 